\begin{abstract}
A developmental intergroup approach was taken to examine the development of prosocial bystander intentions among children and adolescents. Participants as bystanders $(N$ $=260)$ aged 8-10 and 13-15 years were presented with scenarios of direct aggression between individuals from different social groups (i.e., intergroup verbal aggression). These situations involved either an ingroup aggressor and an outgroup victim or an outgroup aggressor and an ingroup victim. The present study focussed on the role of intergroup factors (group membership, ingroup identification, group norms and social-moral reasoning) in the development of prosocial bystander intentions. Findings showed that prosocial bystander intentions declined with age. This effect was partially mediated by the ingroup norm to intervene and perceived severity of the verbal aggression. However, a moderated mediation analysis showed that, only when the victim was an ingroup member and the aggressor an outgroup member, did participants become more likely with age to report prosocial bystander intentions due to increased ingroup identification. Results also showed that younger children focussed on moral concerns and adolescents focussed more on psychological concerns when reasoning about their bystander intention. These novel findings help explain the developmental decline in prosocial bystander intentions from middle childhood into adolescence when observing direct intergroup aggression.
\end{abstract}

Keywords: bystander; aggression; intergroup relations; social-moral reasoning; socialdevelopment 
Children and adolescents who witness bullying and aggression in schools ("bystanders") can be very effective at challenging bullying and aggression among peers (e.g., Craig \& Pepler, 1997; Pozzoli \& Gini, 2010; Salmivalli, 2010). However, only a minority of peers actively intervene to help victims (Hawkins, Pepler \& Craig, 2001). Importantly, as children get older they become less likely to intervene during incidents of bullying or aggression (Rigby \& Johnson, 2006; Trach, Hymel, Waterhouse \& Neale, 2010). Yet little is known about why this developmental decline is observed. Understanding this decline is of both theoretical and practical importance since it could inform interventions to promote prosocial bystander behaviour during childhood and adolescence. The aim of the present study was to utilize a developmental intergroup approach (Killen \& Rutland, 2011; Killen, Mulvey \& Hitti, 2013; Mulvey, Hitti, Rutland, Abrams \& Killen, 2014; Rutland, Hitti, Mulvey,, Abrams \& Killen, in press) to examine how group membership, group identification, group norms, and social-moral reasoning (Rutland, Killen \& Abrams, 2010) can provide further insight into the drivers of this developmental decline. Our focus will be on scenarios of direct aggression between individuals from different social groups (i.e., intergroup verbal aggression).

\section{A Developmental Intergroup Approach}

Research on prosocial bystander responses to incidents of bullying and aggression examines the role of group based factors (i.e., classroom expectations, peer attitudes) as well as individual factors (i.e., self-efficacy, empathy) (e.g., Caravita, DiBlasio \& Salmivalli, 2009; Pozzoli \& Gini, 2010; Salmivalli \& Voeten, 2004). A developmental intergroup approach also highlights the importance of group factors, but uniquely examines the development of bystander responses when there is an ingroup/outgroup context. In such circumstances, intergroup factors such as group membership (i.e., being part of a particular social group such as gender, ethnicity, school), ingroup identification (e.g., the importance of 
belonging to your ingroup) and group norms (e.g., group expectations for attitudes and behaviours) become increasingly relevant to peer evaluations and behavioural intentions with age (see Duffy \& Nesdale, 2012; Abrams, Palmer, Rutland, Cameron \& Van de Vyver, 2013; Abrams \& Rutland, 2011).

The developmental intergroup approach (e.g., Abrams \& Rutland, 2011; Killen, Mulvey \& Hitti, 2013; Rutland, Killen \& Abrams, 2010) has been applied to understand developmental variation in attitudes across contexts of social exclusion (e.g., Abrams et al., 2003), aggression (e.g., Nesdale \& Duffy, 2012) and prosocial behaviour (e.g., Sierksma, Thijs, Verkuyten \& Komter, 2014). To date, no study to our knowledge has employed this approach to specifically examine developmental differences in rates of prosocial bystander intentions from childhood into adolescence.

Abbott and Cameron (2014) examined adolescents' assertive bystander intentions towards only outgroup members and showed these were increased by contact with outgroup members since they heightened empathy and cultural openness and reduced in-group bias. Another study (Nesdale, Killen \& Duffy, 2013) examined children's attitudes towards an aggressor when they either shared group membership with the aggressor, or were independent "third party" observers. This study found that when children shared group membership with the aggressor they were relatively more positive towards them than when they were independent observers. In comparison, the present study specifically focuses on developmental differences in prosocial bystander intentions towards ingroup and outgroup victims across both middle childhood and early adolescence.

Importantly, in the present study, we manipulate membership of both the aggressor and victim, so participants were presented with either an ingroup aggressor/outgroup victim or an outgroup aggressor/ingroup victim. This allowed us to test whether ingroup 
identification motivates children and adolescents to show more prosocial intentions, since previous adult research has demonstrated that individuals who identify strongly with their ingroup are more likely to help ingroup victims compared to outgroup victims in need of help (Levine \& Crowther, 2008; Levine, Prosser, Evans \& Reicher, 2005).

This adult research is in line with social identity developmental theory (SIDT; Nesdale, 2004, 2008) which has shown that stronger ingroup identification amongst children is related to more positive evaluations of members from their ingroup compared to the outgroup (Nesdale \& Duffy, 2011; Nesdale \& Flesser, 2001; Pfeifer et al., 2006). It is reasonable to anticipate that ingroup identification will also influence bystander intentions especially amongst older children. This is because developmental research (see Abrams \& Rutland, 2011) suggests older children with increasing ingroup identification are more likely to be concerned about being excluded from the group for being disloyal (e.g., challenging an ingroup aggressor or not helping an ingroup victim). This research suggests that with age individuals, as they develop stronger ingroup identification, are more likely to help an ingroup victim and not oppose an ingroup aggressor.

Therefore, in the present study, we predict that ingroup identification will mediate the developmental decline in prosocial bystander intentions. Moreover, we expect that group membership of the aggressor/victim will moderate this mediation effect; so that with age and increasing identification with the ingroup, but only when the victim is an ingroup member and the aggressor is an outgroup member, participants' bystander intentions will become increasingly prosocial.

In addition to group membership and identification, from middle childhood into adolescence individuals become more likely to attend to their group's norm when considering appropriate attitudes and behaviours (Abrams \& Rutland, 2008). This is linked to increased 
social perspective taking skills and an enhanced understanding of group dynamics, which enable older children to interpret the complexity of group norms more readily (Abrams, Rutland, Palmer et al, 2014; Killen, Rutland, Abrams, Mulvey \& Hitti, 2013; Nesdale \& Lawson, 2011). In line with these findings bystander research with adolescents has suggested that there might exist a norm for non-intervention among this age group (Aboud \& Joong, 2008). In the present study, to determine whether group norms can help explain the developmental decline in prosocial bystander responses, we measure group norms for intervention. We predict that when adolescents perceive a weaker group norm to intervene they will report lower prosocial bystander intentions.

\section{Social-Moral Reasoning}

As well as examining developmental variations in prosocial bystander intentions, the present study also examined how children and adolescents justify their bystander intentions. Social domain theory states there are three distinct domains of reasoning; moral (concerned with harm, welfare, equality and rights), social-conventional (group identity, group functioning, group norms and authority) and psychological (personal choice and autonomy) (Killen, 2007; Turiel, 1983; Smetana, 1995). A “prudential” domain has also been identified in previous research and refers to reasoning about self-preservation and self-protection (e.g., Smetana \& Asquith, 1994).

Research in this field has consistently shown that younger children focus on moral concerns when evaluating negative peer behaviours (Killen, 2007). However as children get older and become more aware of group dynamics their justifications become more multifaceted (Killen \& Rutland, 2011). Research suggests that adolescents are more able to focus on additional concerns that might arise from intergroup aggression, drawing on social conventional (i.e., "My group says it's OK to say that") or psychological reasons (i.e., "It is 
none of my business; they can say what they like") (see Killen, Rutland et al, 2013; Sierksma et al., 2014). Given these findings, it was expected that younger children would emphasise moral reasoning when justifying their bystander intentions and adolescents would prioritise psychological or social-conventional reasoning.

Research has also shown a developmental trend such that older participants judged negative intergroup acts less severely than younger participants (Killen \& Stangor, 2001). This fits with recent research showing that individuals in middle childhood typically make straightforward moral judgments to condemn negative intergroup acts, whereas adolescents often make multifaceted judgments involving moral, social-conventional or psychological reasoning (Killen et al., 2013; Mulvey, Hitti, Rutland, Abrams \& Killen, 2014). In turn, this means adolescents are less likely to perceive a negative intergroup act as severe (Killen \& Stangor, 2001). To test whether perceived severity mediated age differences in prosocial bystander responses we therefore asked participants to rate the severity of the negative intergroup act.

\section{The Present Study}

The main aim of the present study was to utilize a developmental intergroup approach (drawing on group membership and identification, group norms, and social-moral reasoning) to increase our understanding of why there is a developmental decline in prosocial bystander responses to incidents of bullying and aggression.

We focussed on a broad age range spanning middle childhood (8-10 years) into early adolescence (13-15 years), since previous research has suggested that prosocial bystander responses decline during this period (e.g., Rigby \& Johnson, 2006). Participants were presented with scenarios describing the aggressive act (e.g., Jones, Livingstone \& Manstead., 2012; Nesdale et al., 2013; Sierksma et al., 2014). Verbal aggression was the focus of the 
scenario because it is both a prevalent and overt direct form of aggression that is experienced by both age groups (Smith \& Shu, 2000), and has particularly damaging psychological effects for the victim (Verkuyten \& Thijs, 2002).

The use of scenarios allowed us to experimentally manipulate the group memberships of the aggressor and victim meaning we could examine the above predictions regarding group membership and ingroup identification. Thus, participants either read about an incident involving an ingroup aggressor and an outgroup victim, or an outgroup aggressor and an ingroup victim. In line with previous research on children's intergroup evaluations, the present study focused on a salient social group for both children and adolescents, namely their school membership (e.g., Abrams Rutland, Cameron \& Ferrell, 2007).

\section{Method}

\section{Participants}

Participants were 260 children from the south-east of England from two age groups: "middle childhood" ( $N=110,42.3 \%$, range $=8$ to 10 years, $M=8.77, S D=.67)$ and "early adolescence" $(N=150,57.7 \%$, range $=13$ to 15 years, $M=13.73, S D=7.15)$ and evenly distributed across gender (Female $N=132,51 \%$ ). Participants were from lower to middle class socioeconomic status areas (White British 90\%; White Other 5\%; Black British 2\%; Asian British 3\%).

\section{Design}

The present study followed a 2 (Age group: Middle childhood vs. Early adolescence) x 2 (Group membership: Ingroup aggressor/Outgroup victim vs. Outgroup aggressor/Ingroup victim) between-participants design. Participants were randomly assigned to the group membership conditions: Ingroup victim/Outgroup aggressor $(N=113,56.5 \%)$, Outgroup victim/Ingroup aggressor $N=147,43.5 \%$ ). The key dependent variables were participants' 
bystander intention following a scenario of intergroup verbal aggression, and social-moral reasoning about the decision to intervene or not intervene. Ingroup identification, group norms and perceived severity were measured as potential mediators.

\section{Procedure}

Participants were introduced to gender-matched students; one from their school (named "Boy/Girl A") and another from a fictional outgroup school (named "Boy/Girl B") and presented with a scenario. Participants either read that Boy/Girl A was verbally aggressive towards Boy/Girl B (ingroup aggressor/outgroup victim condition) or that Boy/Girl B targeted Boy/Girl A (outgroup aggressor/ingroup victim condition). For example: Imagine that it is the end of the school day at [ingroup] School. You've been told that it is time to go home. All the children at [ingroup] School are leaving the school to go home. Boy A is with his friends from [ingroup] School. He is standing near the school gate, and Boy B walks past. Boy B doesn't say anything to Boy A, and Boy B isn't looking at Boy A or his friends. You hear Boy A say to Boy B, "You're so boring and stupid! Everyone knows how boring and stupid Meadow Park pupils are! No one likes you because you're from Meadow Park!",l

The stories were accompanied by pictures of the characters. Parental/guardian consent and verbal consent from participants was obtained. Participants completed the measures presented below, before being debriefed and directed to appropriate support if necessary.

\section{Measures}

Ingroup identification. Participants rated three items, adapted from Verkuyten and Thijs (2002) e.g., "I see myself as a [name of ingroup school] pupil”, on a 1 (strongly

\footnotetext{
${ }^{1}$ In this study we used the verbal aggression speech stated above. But in $50 \%$ of the cases participants read about verbal aggression where explicit reference to outgroup membership was omitted $(N=129)$. This betweenparticipant manipulation was included because initially the study had also been designed to examine differences between types of verbal aggression (i.e., group-specific vs. individual). However, for all analyses results showed no significant differences at all in prosocial bystander intentions depending on the type of verbal aggression. In the Discussion we will consider this lack of difference further.
} 
disagree) to 7 (strongly agree) bipolar scale, labelled at either end. The 3 items achieved a reliability of $\alpha=.79$; therefore participant's responses across these three items were averaged to create a measure of ingroup identification.

Prosocial bystander intentions. This measure is derived from previous research (Jones et al., 2012; Palmer \& Cameron, 2010; Trach et al, 2010). Participants indicated their intention to engage in a number of bystander behaviours on a 1 (not very likely) to 7 (very likely) scale, including: "How likely is it that you would tell a teacher or member of staff?; How likely is it that you would tell a friend or member of your family?; How likely is it that you would stand up to Boy/Girl A for Boy/Girl B?; How likely is it that you would ignore the situation?". Intentions to ignore the name-calling act were negatively correlated with the remaining items $(p s<.01)$, so was reverse-coded, and along with the 3 other items achieved a reliability of $\alpha=.69$. These averaged items formed a composite measure of prosocial bystander intentions.

Social-moral reasoning. Participants were first asked, "Do you think that you would tell Boy/Girl A that s/he should not call Boy/Girl B names?” Response options were dichotomous ("yes" or "no"). One hundred sixty-nine participants indicated that they would intervene $(65 \%)$. Participants then reasoned about this intention by responding to the openended question "why". This open-ended response was then coded according to the social domain framework.

Coding and reliability. The framework employed to analyse participants' justifications was based on categories drawn from social domain theory (Smetana, 1995; Killen et al, 2013) and the outcome of pilot testing. The framework consisted of six subcategories of the general codes Moral, Social-conventional, Prudential, and Psychological (see Table 1 for subcategories and examples). These categories were all used more than $10 \%$. Proportional data was used to analyse the participants' use of the coding categories (see 
Killen \& Stangor, 2001; Killen et al., 2013). Coding was conducted by two independent coders. Inter-rater reliability (on $25 \%$ of the justification responses, $N=65$ ) showed $90 \%$ agreement, Cohen's $\kappa=.88$.

Perceived group norm for intervention. Participants read, "If they heard this happen too, how many school children from your school do you think would tell Girl/Boy A that they should not call Girl/Boy B names?" Responses were indicated on a 5 point scale ranging from "none of the children" (1); to "almost all of the children" (5; adapted from Abrams, Rutland, Ferrell \& Pelletier, 2008).

Perceived severity. Participants were asked, "How bad do you think it is for Boy/Girl A to call Boy/Girl B names because he/she is from a different school?” Responses were recorded by circling a number on a 1 (not bad at all) to 6 (very, very bad) bipolar scale (Killen \& Stangor, 2001).

\section{Results}

\section{Preliminary Analysis}

Initial analysis showed no gender differences in prosocial bystander intentions $(F(1$, $\left.251)=.639, p=.425, \eta^{2}=.003\right)$, and as we had no predictions regarding gender differences we controlled for gender in all subsequent analyses (see Table 2 for correlations and descriptive statistics). To check for effects of between-participant variables on bystander intentions, a 2 (Age: middle childhood vs. early adolescence) x 2 (Group membership: Ingroup aggressor/Outgroup victim vs. Outgroup aggressor/Ingroup victim) between-participant ANOVA was performed with prosocial bystander intentions as the dependent variable. Only

age achieved significance, $F(3,258)=41.45, p<.001, \eta^{2}=.34$ (middle childhood $M=5.43$, $\mathrm{SD}=1.11$; early adolescence $M=3.65, S D=1.35)$. As predicted this showed a developmental decline in prosocial bystander intentions. 


\section{Mediation Analyses}

To determine whether ingroup identification, group norms or perceived severity explained the relationship between age and prosocial bystander intentions, a parallel multiple mediation model was run using the PROCESS macro for SPSS (model 4 with 5000 bootstraps). The dichotomous variable age (middle childhood vs. early adolescence) was entered as the independent variable, with prosocial bystander intentions as the dependent variable. As this is a parallel mediation model the order in which the mediators were entered into the model is irrelevant and ignored by PROCESS (Hayes, 2012).

Perceived norm to intervene (indirect effect $=-.19, S E=.07, \mathrm{LLCI}=-.36, \mathrm{ULCI}=-$ .06 ) and perceived severity of the incident (indirect effect $=-.35, S E=.11, \mathrm{LLCI}=-.58$, ULCI $=-.14$ ) both significantly mediated the relationship between age and prosocial bystander intention, as indicated by the absence of a zero between the lower (90\%) and upper (95\%) level confidence intervals. Ingroup identification was not a significant mediator (indirect effect $=-.08, S E=.05, \mathrm{LLCI}=-.20, \mathrm{ULCI}=.01)($ see Table 3 for the unstandardized coefficients for the individual effects of each variable on the prosocial bystander intentions).

Age negatively predicts prosocial bystander intentions (direct path) and negatively predicts norm to intervene. The perceived norm to intervene positively predicts prosocial bystander intentions (Figure 1). When accounting for the mediating role of norms, the coefficient significantly reduces, while remaining negative. This shows that when participants perceive a norm to intervene, the developmental decline in bystander intentions is reduced. Additionally, Figure 1 shows that age negatively predicts the perceived severity of the incident; and that perceived severity positively predicts prosocial bystander intentions. When accounting for the mediating role of perceived severity, the coefficient significantly reduces, 
while remaining negative. This shows that when participants perceive the incident as more severe, the developmental decline in bystander intentions is reduced.

\section{Moderated Mediation: Group Membership and Ingroup Identification}

Next we tested whether group membership of the victim and aggressor moderated a mediating effect of ingroup identification on the age and bystander intention relationship. We expected that with stronger ingroup identification, but only when the victim was an ingroup member and the aggressor an outgroup member, participants would be more likely with age to report prosocial bystander intentions. To test this hypothesis, a moderated mediation (model 8) was performed using the PROCESS macro for SPSS, with 5000 bootstraps.

Findings showed a significant mediation of the age and prosocial bystander intentions relationship through group identification, $\mathrm{B}=-.85, S E=.31, t(252)=-2.70, p=.007, \mathrm{LLCI}=$ -1.47 , ULCI $=-.23$. The predicted moderation mediation effect was found since conditional effects showed the mediation effect was only significant for participants in the condition where an outgroup aggressor targeted an ingroup victim (conditional indirect effect of $\mathrm{X}$ on $\mathrm{Y}$ when ingroup aggressor/outgroup victim: $\mathrm{B}=-.23, S E=.10, \mathrm{LLCI}=-.45, \mathrm{ULCI}=-.07$; whereas when outgroup aggressor/ingroup victim: $\mathrm{B}=-.07, S E=.05, \mathrm{LLCI}=-.20, \mathrm{ULCI}=$ $.00, n s)$ (see Figure 2).

\section{Social-moral reasoning}

To examine differences in type of reasoning about the decision to intervene or not, a 2 (Age: Middle childhood vs. Early adolescence) x 2 (Intention: Intervene vs. Not intervene) x 2 (Group membership: Ingroup aggressor/Outgroup victim vs. Outgroup aggressor/Ingroup victim) x 4 (Reasoning: Moral, Social-conventional, Prudential, Psychological) ANOVA was conducted with repeated measures on the reasoning variable, and gender as a covariate (see Killen, Rutland et al, 2013). 
There was a significant main effect of reasoning $\left(F(1,242)=15.15, p<.001, \eta^{2}=.06\right.$; Moral $M=.54, S D=.50 ;$ Social-conventional $M=.13, S D=.33$; Prudential $M=.08 S D=$ .27 ; Psychological $M=.21, S D=.40)$. Pairwise comparisons showed that moral reasoning was more frequently employed than all other forms of reasoning (all $p s<.001$ ). The use of social-conventional reasoning was significantly lower than moral and psychological reasoning (both $p s<.05)$ but not different to the use of prudential reasoning $(p=.83)$. Psychological reasoning was employed less frequently than moral, but more frequently than social-conventional and prudential reasoning (all $p \mathrm{~s}<.005)$.

Two 2-way interactions were observed: reasoning $\mathrm{x}$ bystander intention $(F(1,242)=$ $\left.147.67, p<.001, \eta^{2}=.38\right)$, and reasoning $\mathrm{x}$ age $\left(F(1,242)=18.76, p<.001, \eta^{2}=.07\right)$. To examine these interactions further, 2 (Age: middle childhood vs. early adolescence) x 2 (Intention: intervene vs. not intervene) x 2 (Group membership: Ingroup aggressor/Outgroup victim vs. Outgroup aggressor/Ingroup victim) univariate ANOVAs were conducted within each level of reasoning.

Moral reasoning. Between-participant effects showed a main effect of age on moral reasoning, $F(1,242)=17.29, p<.001, \eta^{2}=.07$. As expected, children employed more moral reasoning $(M=.74, S D=43)$ compared to adolescents $(M=.39, S D=.49)$. A main effect of intention $\left.(F 1,242)=76.03, p<.001, \eta^{2}=.24\right)$ showed that participants who reported the intention to intervene employed more moral reasoning about their decision $(M=.73, S D=$ $.44)$ compared to those who intended not to intervene $(M=.16, S D=.37)$.

Psychological reasoning. A significant main effect of age $(F(1,242)=17.76$, $\left.p<.001, \eta^{2}=.07\right)$, intention $\left(F(1,242)=33.05, p<.001, \eta^{2}=.12\right)$ and a significant age $\mathrm{x}$ intention interaction $\left(F(1,242)=4.89, p<.05, \eta^{2}=.02\right)$ were observed. As anticipated, adolescents employed psychological reasoning more than children, and those who intended 
not to intervene employed more psychological reasoning than those whose intentions were to intervene. Pairwise comparisons across age groups showed that psychological reasoning was employed more by adolescents (not intervene $M=.55, S D=.50$; intervene $M=.15, S D=.35$ ) than children (not intervene $M=.24, S D=.44$; intervene $M=.02, S D=.13$ ), regardless of intention $(p s<.05)$. When comparing across intentions, pairwise comparisons showed that within each age group psychological reasoning was employed more when intentions were not to intervene, compared to intentions to intervene $(p s<.01)$. This finding shows that psychological reasoning accompanies non-intervention more than intervention intentions, and is more prominent in adolescents' bystander judgements.

Social-conventional reasoning. Between-participant effects showed a marginal effect of intention $\left.(F 1,242)=3.01, p=.08, \eta^{2}=.01\right)$, whereby participants employed more socialconventional reasoning when intending to intervene $(M=.16, S D=.36)$ compared to when they would not intervene $(M=.07, S D=.26)$. A marginal interaction between age and intention $\left.(F 1,242)=3.04, p=.08, \eta^{2}=.01\right)$ was examined within each level of age. In line with predictions, pairwise comparisons showed that children were marginally less likely $(M=$ $.10, S D=.30)$ to employ social-conventional reasoning compared to adolescents $(M=.21$, $S D=.41)$ when reasoning about the intention to intervene $(p=.06)$.

Prudential reasoning. A main effect of intention was observed only $(F(1,242)=$ 48.29, $\left.p<.001, \eta^{2}=.17\right)$. Participants with no intention to intervene employed more prudential reasoning $(M=.24, S D=.42)$ compared to those whose intention was to intervene $(M=.01, S D=.08)$.

\section{Discussion}

This study applied a developmental intergroup perspective (see Killen \& Rutland, 2011; Killen et al., 2013; Rutland et al., 2010) to examine when and why children and 
adolescents intend to respond helpfully as bystanders to verbal aggression between ingroup and outgroup peers. We found a developmental decline in bystander intentions for helping victimized peers in an intergroup context and, for the first time, showed the relevance of group membership and ingroup identification, perceived ingroup norms, and perceived severity of the act to this developmental trend. Both ingroup norms and perceived severity mediated the developmental decline. Importantly we also found that, only when an ingroup victim is targeted by an outgroup aggressor, ingroup identification mediated the relationship between age and bystander intentions.

As anticipated, there was also a developmental trend in participants' reasoning when justifying their bystander intentions. In line with previous research younger children prioritised moral reasoning significantly more than adolescents (e.g., Killen, Rutland et al., 2013) whereas adolescents prioritised psychological reasoning and demonstrated a trend towards employing more social-conventional reasons for their bystander intention compared to children. This finding makes a novel contribution to social domain research by showing for the first time how children reason as bystanders when faced with intergroup verbal aggression. The findings are also consistent with research on intergroup social exclusion showing that as children move into adolescence they weigh up multiple concerns to inform their interpretations of social incidents (e.g., Abrams et al., 2007; Killen, Rutland et al., 2013).

The present study makes an original contribution by identifying some of the intergroup processes behind the developmental decline in bystander intentions. Additionally, we build on existing research that shows the relevance of intergroup processes for children and adolescents' social interactions (see Abrams \& Rutland, 2008; Fitzroy \& Rutland, 2010; Killen \& Rutland, 2011; Killen et al., 2013; Nesdale, 2008; Sierksma et al., 2014), and extend 
it further by applying this approach to bystander intentions during incidents of intergroup verbal aggression.

Taken together, these results advance our understanding of when and why children and adolescents help ingroup and outgroup peers who experience intergroup verbal aggression. Importantly, results reiterate the relevance of examining the developmental decline in prosocial bystander responses from an intergroup perspective. Results suggest that, in comparison to their older counterparts, younger children may view prosocial bystander behaviour as the most morally appropriate response to engage in, regardless of the group norm. These findings emphasise the requirement of age-tailored interventions in order to promote prosocial bystander responses.

\section{Limitations and future directions}

The current research focused on intergroup verbal aggression, where the group membership of the victim and aggressor was varied to be either an ingroup or an outgroup member to the participant-bystander. This was necessary to test our predictions regarding the role of group membership and ingroup identification in the developmental decline of prosocial bystander intentions. In order to maintain the intergroup nature of the bullying scenario this meant that the group membership of the aggressor was always in contrast to that of the victim (i.e., an ingroup aggressor targeted an outgroup victim, or an outgroup aggressor targeted an ingroup victim).

We acknowledge that by manipulating the intergroup context in this way it is not possible to determine whether the group membership of the victim or the aggressor led to the observed moderated mediation. However, we suggest that our findings point to the victim group membership being the most likely influence on the participants' bystander intentions for two key reasons. First, participants reported their ingroup identification and this was only a mediator when the victim was an ingroup member and not when the aggressor was an 
ingroup member. Second, in the former condition, we asked participants to indicate their prosocial bystander intentions towards the victim and not their response to toward the aggressor.

More generally, research based upon social identity development theory supports the interpretation that the ingroup membership of the victim would drive the participant's bystander response given they both share the same group membership and ingroup identification develops early in childhood (e.g., Nesdale, 2008). Adult research utilizing social identity theory also suggests that ingroup victims compared to outgroup victims are warranted special attention when engaging in prosocial helping behaviour (e.g., Levine et al., 2005). However, future research should examine a range of aggressor/victim or possibly third-party group membership combinations in bystander intergroup contexts to conclusively support this interpretation.

A further consideration is the lack of difference in type of verbal aggression targeted at the victim. In the original design of the present study we anticipated that verbal aggression targeted at a victim's group membership might be perceived more severely, and therefore result in more prosocial bystander intentions, compared to verbal aggression targeted at the victim (e.g., Killen \& Stangor, 2001). However, no differences were observed across these conditions (consequently data were combined for analyses). We propose that this lack of an effect was due to the salience of ingroup and outgroup memberships presented before the scenario; participants always read that the aggressor was from one school and the victim was from another. It is probable, therefore, that all verbal aggression was perceived as intergroup regardless of the phrasing of the name-calling. To test this supposition further future research should ensure that verbal aggression targeted at the individual is unambiguous.

The present findings also indicate fruitful areas for future research, for example examining children's prosocial bystander intentions in response to different forms of 
intergroup aggression (Nesdale et al., 2013), as different aggressive behaviours may be considered more or less severe thus impacting the likelihood of prosocial bystander responses. In addition, findings might differ across alternative intergroup contexts such as ethnicity (Abbott \& Cameron, 2014; Mulvey et al., 2014) as well as different combinations of bystander, victim and aggressor group memberships (Nesdale et al., 2013).

Within the present study predictors of bystander intentions were the focus. The authors acknowledge that intentions are not the same as actual behaviours. However, research conducted in the context of prosocial interactions has shown how intentions are strongly indicative of actual behaviour (e.g., Smith \& McSweeney, 2007). To strengthen the current findings it would be important to replicate the study by employing mixed methodologies, including observational designs (Duffy \& Nesdale, 2012) and peer-nomination (Salmivalli, 2010; Monks, Smith \& Swettenham, 2003; Obermann, 2011).

In conclusion, this study identified key intergroup processes involved in the developmental decline of bystander intentions to intervene, namely group membership and ingroup identification, group norms, perceived severity of the act and social-moral reasoning. The findings of this study highlight the importance of considering intergroup processes in addition to interpersonal processes when seeking to promote prosocial bystander responses across different age groups, which may in turn reduce incidents of aggression in schools. Our findings suggest that, particularly among older participants, promoting a group norm for helpful intervention when faced with intergroup verbal aggression, combined with an emphasis on the severity of the act and a moral obligation to treat all peers fairly, could be an effective strategy when promoting prosocial bystander intervention in school. 


\section{References}

Abbott, N.J., \& Cameron, L. (2014). What makes a young assertive bystander?: The effect of intergroup contact, empathy, cultural openness and ingroup bias on assertive bystander intervention intentions. Journal of Social Issues.

Aboud, F. \& Joong, A. (2008). Intergroup name-calling and conditions for creating assertive bystanders. In S.R. Levy \& M. Killen (Eds.), Intergroup attitudes and relations in childhood through adulthood (pp. 249-260). New York: Oxford University Press.

Abrams, D., \& Rutland, A. (2008). The development of subjective group dynamics. In S.R. Levy \& M. Killen (Eds.), Intergroup attitudes and relations in childhood through adulthood (pp. 47-65). Oxford: Oxford University Press.

Abrams, D. \& Rutland, A. (2011). Children's understanding of deviance and group dynamics: The development of subjective group dynamics. In J. Jetten \& M. J. Hornsey (Eds.), Rebels In Groups: Dissent, Deviance, Difference and Defiance. Oxford: WileyBlackwell.

Abrams, D., Rutland, A., \& Cameron, L. (2003). The development of subjective group dynamics: Children's judgments of normative and deviant in-group and out-group individuals. Child Development, 74, 1840-1856. doi:10.1046/j.14678624.2003.00641.x

Abrams, D., Rutland, A., Ferrell. J.M., \& Pelletier, J.(2008). Children's judgments of disloyal and immoral peer behavior: Subjective group dynamics in minimal intergroup contexts. Child Development, 79, 444-461. doi:dx.doi.org/10.1111/j.14678624.2007.01135.x

Abrams, D., Rutland, A., Cameron, L. \& Ferrell, J.M. (2007). Older but wilier: Ingroup accountability and the development of subjective group dynamics. Developmental Psychology, 43, 134-148.doi:10.1037/0012-1649.43.1.134 
Abrams, D., Palmer, S. B., Rutland, A., Cameron, L., \& Van de Vyver, J. (2013). Evaluations of and Reasoning About Normative and Deviant Ingroup and Outgroup Members: Development of the Black Sheep Effect. Developmental Psychology. [Online April 1] doi:10.1037/a0032461

Abrams, D., Rutland, A., Palmer, S.B., Pelletier, J., Ferrell, J., \& Lee, S. (2014). The role of cognitive abilities in children's inferences about social atypicality and peer exclusion and inclusion in intergroup contexts. British Journal of Developmental Psychology, [online, early view]. doi:10.1111/bjdp.12034

Caravita, S.C., DiBlasio, P. \& Salmivalli, C. (2009). Unique and interactive effects of empathy and social status on involvement in bulling. Social Development, 18, 140163. doi:10.1111/j.1467-9507.2008.00465.x

Craig, W.M. \& Pepler, D.J. (1997). Observations of bullying and victimization in the school yard. Canadian Journal of School Psychology, 13, 41-59. doi:10.1177/082957359801300205

Duffy, A. \& Nesdale, D. (2012). Understanding childhood aggression: A social identity perspective. In B.C. Guevara \& N.A. Becerra (Eds.), Psychology of aggression: New research (pp.99-117). Hauppauge NY: Nova Science.

Fitzroy, S. \& Rutland, A. (2010). Learning to control ethnic intergroup bias in children. European Journal of Social Policy, 40, 679-693. doi:10.1002/ejsp.746

Hawkins, D.L., Pepler, D.J. \& Craig, W.M. (2001). Naturalistic observations of peer interventions in bullying. Social Development, 10 (4), 512-527. doi:10.1111/14679507.00178

Hayes, A.F. (2012). PROCESS: A versatile computational tool for observed variable mediation, moderation and conditional process modelling [White paper]. Retrieved from http://www.afhayes.com/ 
Jones, S.E., Livingstone, A.G., \& Manstead, A.S.R. (2012). Fair-weather or foul-weather friends? Group identification and children's responses to bullying. Social Psychological and Personality Science, 4, 414-420.doi: 10.1177/1948550611425105

Killen, M. (2007). Children's social and moral reasoning about exclusion. Current Directions in Psychological Science, 16, 32-36. doi:10.1111/j.1467-8721.2007.00470.x

Killen, M., Mulvey, K.L., \& Hitti, A. (2013). Social exclusion: A developmental intergroup perspective. Child Development, 84, 772-790.doi: 10.1111/cdev.12012

Killen, M., \& Rutland, A. (2011). Children and social exclusion: Morality, prejudice and group identity. Wiley Blackwell.

Killen, M., Rutland, A., Abrams, D., Mulvey, K. L. \& Hitti. A. (2013). Development of intraand intergroup judgments in the context of moral and social-conventional norms. Child Development, 84, 1063-1080. doi: 10.1111/cdev.12011

Killen, M. \& Stangor, C. (2001). Children's social reasoning about inclusion and exclusion in gender and race peer group contexts. Child Development, 72, 174-186. doi: $10.1111 / 1467-8624.00272$

Levine, M. \& Crowther, S. (2008). The responsive bystander: How social group membership and group size can encourage as well as inhibit bystander intervention. Journal of Personality and Social Psychology, 95, 1429-1439. doi: 10.1037/a0012634.

Levine, M., Prosser, A., Evans, D., \& Reicher, S. (2005). Identity and emergency intervention: How social group membership and inclusiveness of group boundaries shape helping behavior. Personality and Social Psychology Bulletin, 31, 443-453. doi: $10.1037 / \mathrm{a} 0012634$

Monks, C.P., Smith, P.K., \& Swettenham, J. (2003). Aggressors, victims, and defenders in preschool: Peer, self-, and teacher reports. Merrill-Palmer Quarterly, 49, 453-469. doi:10.1353/mpq.2003.0024 
Mulvey, K.L., Hitti, A., Rutland, A., Abrams, D., \& Killen, M. (2014). Context differences in children's ingroup preferences. Developmental Psychology, 50, 1507-1519. doi:10.1037/a0035593

Nesdale, D. (2008). Social identity development and children's ethnic attitudes in Australia. In S. Quintana \& C. McKown (Eds.), Handbook of Race, Racism, and the Developing Child (pp. 313-338). New Jersey: John Wiley \& Sons, Inc.

Nesdale, D., Killen, M., \& Duffy, A. (2013). Children's social cognition about proactive aggression. Journal of Experimental Child Psychology, 116, 674-692. doi: org/10.1016/j.jecp.2013.07.003

Nesdale, D., \& Flesser, D. (2001). Social identity and the development of children's group attitudes. Child Development, 72, 506-517. doi: 10.1111/1467-8624.00293

Nesdale, D., \& Lawson, M.J. (2011). Social groups and children's intergroup attitudes: Can school norms moderate the effects of social group norms? Child Development, 82, 1594-1606. doi:10.1111.j.1467-8624.2011.01637.x

Obermann, M.L. (2011). Moral disengagement among bystanders to school bullying. Journal of School Violence, 10, 239-257. doi:10.1080/15388220.2011.578276

Palmer, S. \& Cameron, L. (2010, July). Bystander intervention in subtle and explicit racist incidents. Paper presented at EASP small group meeting on 'Developmental Perspectives on Intergroup Prejudice: Advances in Theory, Measurement, and Intervention', Lisbon, Portugal.

Pfeifer, J.H., Ruble, D.N., Bachman, M.A., Alvarez, J.M., Cameron, J.A. \& Fuligni, A.J. (2006). Social identities and intergroup bias in immigrant and non-immigrant children. Developmental Psychology, 43, 496-507. doi: http://dx.doi.org/10.1037/0012-1649.43.2.496 
Pozzoli, T.\& Gini, G. (2010). Active defending and passive bystanding behavior in bullying: The role of personal characteristics and perceived peer pressure. Journal of Abnormal Child Psychology, 38, 815-827. doi:10.1007/s10802-010-9399-9

Rigby, K. \& Johnson, B. (2006). Expressed readiness of Australian schoolchildren to act as bystanders in support of children who are being bullied. Educational Psychology, 26, 425-440. doi:10.1080/01443410500342047

Rutland, A., Killen, M., \& Abrams, D. (2010). A new social-cognitive developmental perspective on prejudice: The interplay between morality and group identity. Perspectives on Psychological Science, 5, 279-291. doi: 10.1177/1745691610369468.

Rutland, A., Hitti, A., Mulvey, K. L, Abrams D. \& Killen, M. (in press). When does the ingroup like the out-group?: Bias among children as a function of group norms. Psychological Science.

Salmivalli, C. (2010). Bullying and the peer group: A review. Aggression and Violent Behaviour, 15 (2), 112-120. doi:10.1016/j.avb.2009.08.007

Salmivalli, C. \& Voeten, M. (2004). Connections between attitudes, group norms, and behavior in bullying situations. International Journal of Behavioral Development, 28 (3), 246-258. doi:10.1080/01650250344000488

Sierksma, J.,Thijs, J., Verkuyten, M., \& Komter, A. (2014). Children's reasoning about the refusal to help: The role of need, costs and social perspective taking. Child Development, 85, 1134-1149. doi:10.111/cdev.12195

Smetana, J. G., \& Asquith, P. (1994). Adolescents' and parents' conceptions of parental authority and adolescent autonomy. Child Development, 65, 1147-1162. doi: $10.2307 / 1131311$

Smetana, J.G. (1995). Parenting styles and conceptions of parental authority during adolescence. Child Development, 66, 299-316. doi: 10.2307/1131579 
Smith, J.R., \& McSweeney, A. (2007). Charitable giving: the effectiveness of a revised theory of planned behaviour model in predicting donating intentions and behaviour. Community and Applied Social Psychology, 17, 363-386. doi:10.1002/casp.906

Smith, P.K. \& Shu, S. (2000). What good schools can do about bullying: Findings from a survey in English schools after a decade of research and action. Childhood: A Global Journal of Child Research, 7 (2), 193-212. doi:10.1177/0907568200007002005

Trach, J. Hymel, S., Waterhouse, T., \& Neale, K. (2010). Age differences in bystander responses to school bullying: A cross-sectional investigation. Canadian Journal of School Psychology, 25 (1), 114-130. doi:10.1177/0829573509357553

Turiel, E. (1983). The development of social knowledge: Morality and convention. Cambridge: Cambridge University Press.

Verkuyten, M., \& Thijs, J. (2002). Racist victimization amongst children in the Netherlands: The effect of ethnic group and school. Ethnic and Racial Studies, 25 (2), 310-331. doi:10.1080/01419870120109502 
Table 1

Social-moral reasoning categories, subcategories in italics, and examples of participant responses within each category

Moral Examples

Perpetrator inflicting harm

Equality and fairness

Empathy and perspective-taking
"Because it's a form of bullying"

"It is not a nice way to treat other people"

“Because everyone is important, it doesn't matter what school you go to"

"Because it might not matter to that girl but she will probably feel hurt inside"

\section{Social-conventional}

Social expectations and outcomes "If I did not tell [the perpetrator], she would keep calling [the victim] names"

\section{Prudential}

Self-preservation

$$
\begin{aligned}
& \text { "Because if I got involved it would be me that } \\
& \text { would get bullied as well as [victim]" }
\end{aligned}
$$

\section{Psychological}

Personal choice

“Because it's none of my business, I don't want to get involved"

Note. All categories used more than $10 \%$; both positive and negative references to each category are included within each category 
Table 2

Bivariate correlation matrix for key study variables, along with means $(M)$ and standard deviations (SD)

\begin{tabular}{lcccccc}
\hline & 1 & 2 & 3 & 4 & $M$ & $S D$ \\
\hline 1. Age & - & & & & 1.58 & .50 \\
2.Perceived norm & $-.391^{* *}$ & - & & & 2.91 & 1.30 \\
3.Perceived severity & $-.446^{* *}$ & $.269^{* *}$ & - & & 4.75 & 1.24 \\
4.Ingroup identification & $-.297^{* *}$ & $.286^{* *}$ & $.261^{* *}$ & - & 5.38 & 1.31 \\
5.Prosocial bystander & $-.574 * *$ & $.389 * *$ & $.488^{* *}$ & $.307 * *$ & 4.40 & 1.53 \\
intentions & & & & & &
\end{tabular}

Note. ${ }^{*}$ correlation is significant at $p<.05,{ }^{* *}$ correlation is significant at $p<.01$. 
Table 3

Statistics for the individual effects of each predictor variable on prosocial bystander intentions.

\begin{tabular}{lcccccc}
\hline \multicolumn{1}{c}{ Variable } & B & $S E$ & $t$ & $p$ & LLCI & ULCI \\
\hline Age (middle childhood & -1.12 & .18 & -6.41 & $>.0001$ & -1.47 & -.78 \\
vs. early adolescence) & & & & & & \\
Perceived norm & .18 & .06 & 2.95 & $>.005$ & .06 & .31 \\
Perceived severity & .32 & .07 & 4.73 & $>.0001$ & .18 & .45 \\
Ingroup identification & .10 & .06 & 1.71 & $=.09$ & -.02 & .22 \\
Gender (controlled) & .11 & .15 & .72 & $=.47$ & -.19 & .40 \\
\hline Note. Degrees of freedom for $t$-test: df1=5, df2=249. All statistics rounded to 2 decimal \\
places.
\end{tabular}




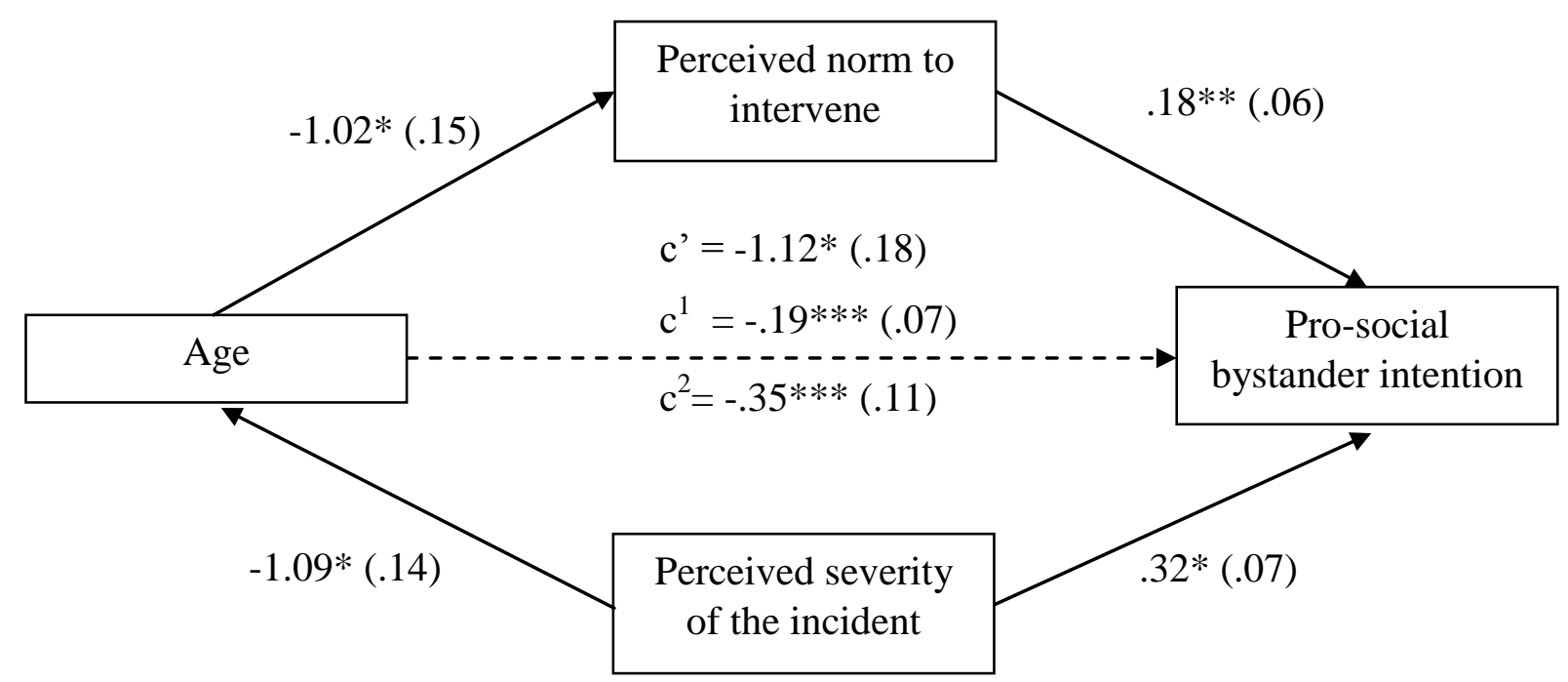

Figure 1.Parallel multiple mediation of age and prosocial bystander intentions through (1) the perceived norm to intervene, and (2) perceived severity of the incident. Unstandardized regression coefficients are provided along the paths, with error terms in parentheses. Note. c' $=$ direct path between age and prosocial bystander intentions, $c^{1}=$ indirect path (mediation through perceived norm), $\mathrm{c}^{2}=$ indirect path (mediation through perceived severity). $*=$ $p<.0001, * *=p<.005 . * * *=$ no zero between LLCI and ULCI. 


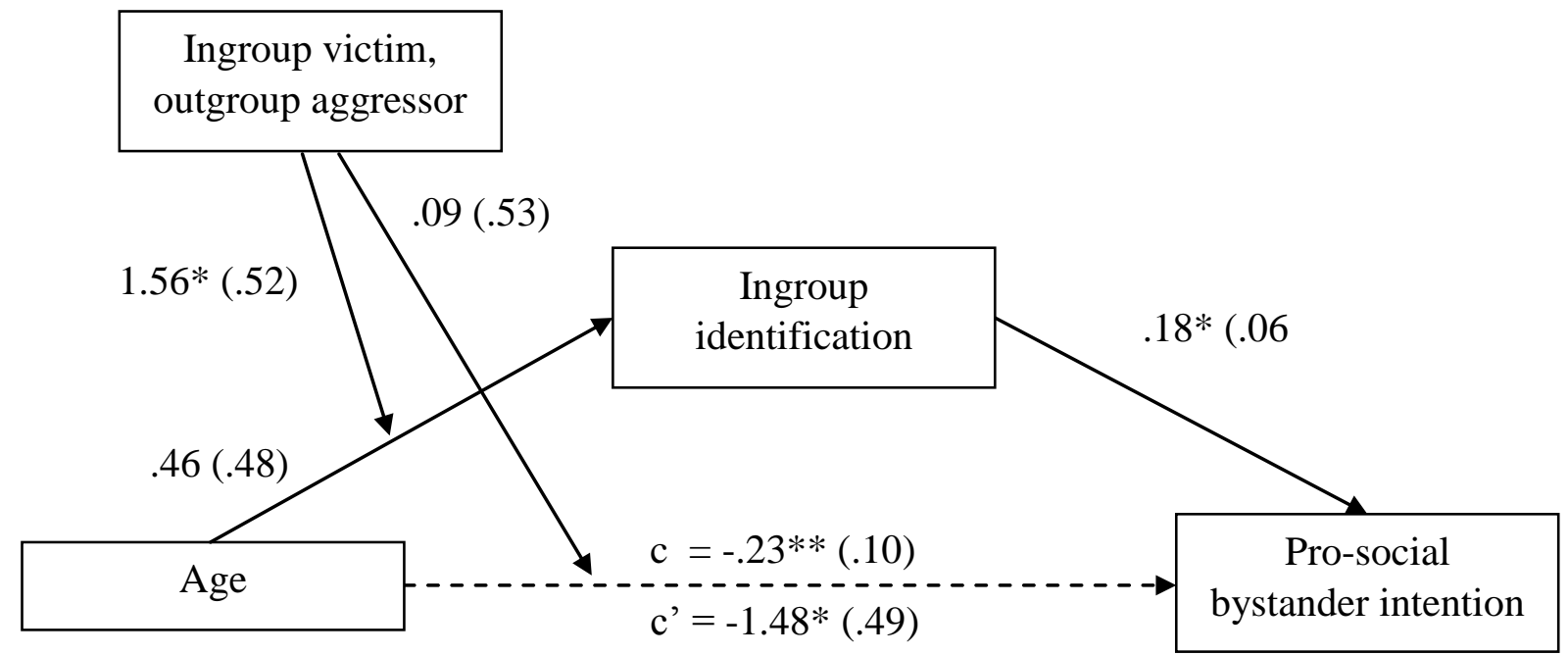

Figure 2. Moderated mediation of age and prosocial bystander intentions through social identification when group membership = victim ingroup/aggressor outgroup. Unstandardized regression coefficients are provided along the paths, with error terms in parentheses. Note. c' $=$ direct path, $\mathrm{c}=$ indirect path. $*=p<.005 . * *=$ no zero between LLCI and ULCI. 